\title{
Peran Perceived Organizational Support terhadap Work Engagement Karyawan
}

\author{
The Role of Perceived Organizational Support towards \\ Employee Work Engagement
}

\author{
Jufi Lailatul Mufarrikhah ${ }^{1}$, Muhammad Salis Yuniardi ${ }^{2}$, Nandy Agustin Syakarofath ${ }^{3}$ \\ Fakultas Psikologi, Universitas Muhammadiyah Malang
}

Submitted 30 Mei 2020

Accepted 30 September 2020

Published 27 Oktober 2020

\begin{abstract}
Work engagement is an attitude that depicts an individual fully engaging with his or her work both emotionally and physically by exhibiting passionate, dedicated, and imaginary behaviour in doing the work. One of the factors that can play a role in improving work engagement is perceived organizational support, namely employee perception of support, care and organizational contribution to the welfare of its employees. The purpose of this research was to test the role of perceived organizational support towards employee work engagement. The subjects of this study were 300 employees in the field of services and products obtained using quota sampling techniques. Research instruments used were 13 items of SPOS (Survey Perceived Organizational Support) and UWES-17 (Utrecht Work Engagement Scale-17) with 17 items. Data analysis using simple linear regression techniques with perceived organizational support results plays a positive role in employee work engagement (Value $F=152.442, P=0.000<0.005$ ). Meanwhile, effective contributions made by perceived organizational support can predict work engagement of $33.8 \%$. That is, perceived organizational support is proven to have a role against high low employee work engagement.
\end{abstract}

Keywords: employees; perceived organizational support; work engagement

Abstrak. Work engagement adalah sikap yang menggambarkan individu secara penuh terlibat dengan pekerjaannya, baik secara emosi maupun fisik dengan menunjukkan perilaku yang penuh semangat, penuh dedikasi, dan penghayatan dalam menunaikan pekerjaan. Salah satu faktor yang dapat berperan dalam meningkatkan work engagement adalah perceived organizational support, yaitu persepsi karyawan mengenai dukungan, kepedulian dan kontribusi organisasi terhadap kesejahteraan karyawannya. Tujuan penelitian ini adalah untuk menguji peran perceived organizational support terhadap work engagement karyawan. Subjek penelitian ini sejumlah 300 karyawan di bidang jasa dan produksi yang diperoleh menggunakan teknik quota sampling. Instrumen penelitian menggunakan SPOS (Survey Perceived Organizational Support) sebanyak 13 aitem dan UWES-17 (Utrecht Work Engagement Scale-17) sebanyak 17 aitem. Analisis data menggunakan teknik regresi linier sederhana dengan hasil perceived organizational support berperan positif terhadap work engagement karyawan (Nilai $F=152,442 ; p=<0,005$ ). Adapun, sumbangan efektif yang diberikan oleh perceived organizational support dapat memprediksi work engagement sebesar 33,8\%. Artinya, perceived organizational support terbukti memiliki peran terhadap tinggi rendahnya work engagement karyawan.

Kata kunci: karyawan; perceived organizational support; work engagement

Korespondensi mengenai artikel ini dapat dilakukan melalui nandysyakarofath@umm.ac.id 
Perubahan lingkungan dan pesatnya teknologi terkini dapat meningkatkan kompleksitas tantangan yang dihadapi perusahaan. Tantangan tersebut tidak terlepas kaitannya dengan sumber daya yang dimiliki karena ia merupakan aset yang dimiliki perusahaan untuk mencapai tujuan organisasi. Sumber daya yang dimiliki perusahaan dapat dikategorikan menjadi empat tipe sumber daya, yaitu finansial, fisik, manusia, dan kemampuan teknologi. Salah satu sumber daya terpenting yang ada di perusahaan tersebut ialah sumber daya manusia (Priyono \& Marnis, 2008). Hasibuan (2012) menyebutkan sumber daya manusia adalah segenap aktivitas yang bersangkutan dengan masalah penggunaan tenaga kerja manusia dalam suatu usaha kerja sama untuk mencapai tujuan tertentu.

$$
\text { Okoye dan Ezejiofor }
$$

menyebutkan keberhasilan berkembangnya organisasi disebabkan oleh faktor manusianya, hal ini disebabkan karena manusia adalah roda penggerak jalannya organisasi. Di Indonesia, menurut Hay Group and Center for Economics dan Business Research, angka turnover karyawan cukup tinggi dibandingkan negara-negara lainnya yang cukup maju seperti Amerika Serikat, Australia, Kanada, Jerman, Inggris, dan Belanda. Hal ini terlihat sejak tahun 2015 pada data yang diperoleh dari laporan the Michael Page Indonesia Employee Intentions bahwasanya terdapat $72 \%$ responden yang tertarik berpindah kerja setelah 12 bulan pertama bekerja (Alkhatiri, 2017). Data lain menyebutkan hal serupa bahwa 65,8\% generasi milenial di Indonesia memilih meninggalkan perusahaan tempat mereka bekerja setelah 12 bulan (Lie \& Andreani (2017). Dampak dari turnover tersebut berpengaruh terhadap stabilitas jalannya organisasi. Padahal, kebutuhan perusahaan untuk menginvestasikan energi dan biaya terhadap sumber daya yang dimiliki sebesar $75 \%$ sedangkan sisanya $10 \%$ untuk peralatan dan teknologi dan 15\% untuk sistem perencanaan (Amir, 2015). Kondisi ini mempertegas pentingnya sumber daya manusia dalam sektor industri.

Tinggi rendahnya turnover karyawan disebutkan berkaitan erat dengan work engagement (Hermawan, Hartika, \& Simarmata, 2017; Lu, Lu, Gursoy \& Neale, 2016) dan performansi kerja (Sekhar, Patwardhan \& Vyas, 2018). Mengingat sumber daya manusia sebagai faktor penentu kemajuan organisasi maka penting bagi karyawan untuk merasa terikat dengan pekerjaannya dan berkomitmen di dalamnya (work engagement). Work engagement adalah keadaan di mana seseorang mampu berkomitmen dengan organisasi, baik secara emosional maupun secara intelektual (Lockwood, 2007). Dampak work engagement yang dimiliki karyawan dapat memaksimalkan pekerjaan yang ditangani (Robert, 2006). Bahkan Lockwood (2007) memaparkan aspek penentu organisasi tumbuh dan berkembang adalah pasar yang kompetitif dan sumber daya yang mendukung. Oleh karenanya work engagement perlu menjadi salah satu fokus perusahaan.

Work engagement dapat membuat karyawan merasa lebih positif terhadap pekerjaanya. Crawford, Lepine, dan Rich, (2010) menyebutkan bahwa work 
engagement yang dimiliki karyawan dapat membuat pekerjaan terasa lebih mudah dan menarik serta senantiasa termotivasi mencari tantangan akan hal baru. Dampaknya, karyawan diliputi pemikiran yang positif terhadap pekerjaannya dan lebih produktif (Harter, Schmidt, \& Hayes, 2002). Sejalan dengan pernyataan tersebut, work engagement dapat membuat karyawan lebih sehat secara fisik dan psikologis sehingga secara otomatis dipenuhi emosi yang positif dan lebih produktif (Bakker \& Demerouti, 2008). Dampak lain dari work engagement adalah kualitas kerja semakin membaik, meminimalisasi konflik, kinerja tinggi, dan hasil bisnis yang positif (Hallberg \& Schaufeli, 2006; Saks, 2006; Schaufeli dan Bakker, 2004). Artinya work engagement dapat memberikan energi positif bagi karyawan dan organisasi.

Trend work engagement di Indonesia digambarkan rendah. Hafiz (2018) memaparkan tingkat work engagement pada pegawai ASN yang mendominasi angka tertinggi adalah low-moderate yaitu 77,84\%, sedangkan sisanya $22,16 \%$ disebutkan cukup bagus. Data lain konsisten menyebutkan perbandingan workengagement karyawan lebih banyak didominasi yang rendah sebesar 81,10\%, sisanya work-engagement yang rendah sebesar 18,90\% (Anggiadinata, 2015). Begitu juga temuan yang menyebutkan karyawan yang memiliki work-engagement yang bagus di sebuah perusahan hanya sebesar 13\%, sisanya 87\% rendah (Mewengkang \& Panggabean, 2016). Artinya, dari berbagai penelitian ditemukan konsistensi work engagement rendah dengan jumlah tidak lebih dari 25\% dari subjek yang diteliti.

Faktor penyebab work-engagement bervariasi dan secara umum terbagi menjadi dua faktor yaitu internal dan eksternal. Faktor eksternal yang dianggap berkontribusi adalah organizational citizenship behavior (Fatoni, Prihatini \& Suryaningsih, 2018), organizational culture (Shehri, McLaughlin, Al-Ashaab \& Hamad, 2017) dan dukungan sosial (Bakker \& Demerouti, 2007). Sedangkan pada faktor internal adalah self efficacy (Davids, 2011), self esteem (Rotich, Cheruiyot, \& Korir, 2016). Dijelaskan bahwa karyawan dengan self efficacy dan self esteem yang tinggi cenderung memiliki work engagement yang baik. Kedua faktor tersebut, baik eksternal dan internal sama-sama kuat berdampak terhadap work-engagement, namun demikian peneliti memfokuskan pada faktor internal. Hal ini didasarkan pada temuan Kahn (1990) yang menganggap rasa aman, perasaan bermakna, dan kepuasan yang dirasakan karyawan merupakan faktor yang paling berperan terhadap workengagement. Temuan tersebut dipertegas oleh John dan Pant (2018) yang memaparkan bahwa kepuasan karyawan dipengaruhi oleh work engagement.

Rasa aman, perasaan bermakna, dan kepuasan yang dirasakan karyawan tidak terlepas dari adanya dukungan penuh dari organisasi. Dukungan organisasi terhadap karyawan adalah upaya mewujudkan kesejahteraan dan berbagai penghargaan yang dapat diberikan atas kontribusi dan evaluasi dari kinerja karyawan. Kedua aspek tersebut disebut dengan istilah organizational support (Eisenberger et al., 
1986). Berdasarkan pemahaman tersebut, karyawan yang mendapatkan dukungan yang positif dari organisasi akan mempersepsikan secara positif dukungan tersebut, begitu juga sebaliknya kurangnya dukungan dari organisasi akan memberikan evaluasi yang negatif dari karyawan di mana keduanya menentukan work engagement \& kinerja karyawan (Rhoades \& Eisenberger, 2002). Oleh karenanya, persepsi karyawan atas dukungan yang diberikan oleh perusahaan menjadi menarik untuk dikaji lebih mendalam karena dapat menentukan bagaimana karyawan tersebut bersikap saat bekerja. Inilah landasan yang membuat peneliti tertarik untuk mengaitkan perceived organizational support dengan work engagement.

Rumusan masalah yang diangkat dalam penelitian ini adalah perceived organizational support berperan terhadap work engagement pada karyawan. Manfaat penelitian ini secara teoritis diharapkan mampu memberikan informasi peran nyata perceived organizational support terhadap work engagement karyawan sehingga temuan dapat menjadi sumber literasi atau bahan acuan bagi praktisi dan peneliti pemerhati industri dan organisasi untuk merumuskan kebijakan atau pengembangan penelitian sebagai bentuk dukungan organisasi terhadap karyawan dan mampu meningkatkan engagement setiap individu yang berada di dalam organisasi tersebut.

\section{Metode}

Penelitian ini dilakukan dengan menggunakan metode kuantitatif. Subjek penelitian ini merupakan 300 orang karyawan tetap dan karyawan non-tetap dari 4 jenis perusahaan yaitu; 1) perusahaan jasa swasta, 2) perusahaan jasa pemerintah, 3) perusahaan produksi swasta, 4) perusahaan produksi pemerintah yang berlokasi di Jawa Timur. Teknik sampling penelitian ini menggunakan Quota Sampling. Menurut Sugiyono (2010), quota sampling adalah teknik sampling yang menentukan jumlah sampel dari populasi yang memiliki ciri tertentu sampai jumlah kuota (jatah) yang diinginkan.

\section{Instrumen penelitian}

Instrumen yang digunakan dalam penelitian ini adalah : 1) Survey Perceived Organizational Support (SPOS) yang disusun oleh Eisenberger, Huntington, Hutchison dan Sowa (1986) terdiri dari tiga dimensi yakni keadilan prosedural, dukungan atasan, dan penghargaan organisasi \& kondisi pekerjaan. Adapun skala SPOS tersebut telah diterjemahkan ke dalam bahasa Indonesia oleh Kusumandaru (2017) dengan indeks reliabilitas sebesar 0,830. 2) Skala Utrecht Work Engagement Scale-17 (UWES-17) yang disusun oleh Schaufeli, Salanova, Gonzalez-Roma, dan Bakker (2002) dan telah diterjemahkan ke dalam bahasa Indonesia oleh Mustofa (2019). Skala tersebut terdiri dari tiga dimensi yakni vigor, dedication, dan absorption dengan indeks reliabilitas sebesar 0,909. Kedua skala tersebut memiliki empat pilihan pernyataan yaitu, sangat setuju (SS), setuju (S), tidak setuju (TS), dan sangat tidak Setuju (STS). Data dikumpulkan melalui 
penyebaran skala yang dilakukan dengan dua cara yaitu mendatangi perusahaan langsung dan dilakukan secara online menggunakan google form dan disebarkan melalui media sosial seperti whatsapp. Untuk memastikan kesediaan subjek dan kesesuaian kriteria sebelum mengisi terlebih dahulu diberikan informed consent. perusahaan produksi pemerintah yang berlokasi di Jawa Timur. Secara terperinci, data demografi subjek penelitian yang terkumpul dapat dilihat pada Tabel 1.

Tabel 1 memaparkan secara terperinci persentase jumlah subjek laki-laki lebih banyak dibandingkan perempuan, di mana jumlah subjek laki-laki 52,7\% dan subjek

Tabel 1.

Data Demografi Subjek Penelitian

\begin{tabular}{llcc}
\hline \multicolumn{1}{c}{ Klarifikasi } & Kategori & Frekuensi & Persentase (\%) \\
\hline Gender & Laki-Laki & 158 & $52,7 \%$ \\
& Perempuan & 142 & $47,3 \%$ \\
& Total & 300 & $100 \%$ \\
\hline Usia & 18-28 Tahun & 203 & $67,7 \%$ \\
& 29-39 Tahun & 66 & $22 \%$ \\
& 40-50 Tahun & 20 & $6,7 \%$ \\
& 51-60 Tahun & 11 & $3,6 \%$ \\
& Total & 300 & $100 \%$ \\
\hline Masa Kerja & 1-5 Tahun & 214 & $71,3 \%$ \\
& T5 & 86 & $28,7 \%$ \\
& Total & 300 & $100 \%$ \\
\hline Status Karyawan & Non-tetap / Kontrak / Outsourcing & 145 & $48,3 \%$ \\
& Tetap/Masa Pendidikan Kerja & 155 & $51,7 \%$ \\
& Total & 300 & $100 \%$ \\
\hline
\end{tabular}

\section{Analisis data}

Analisa data dalam penelitian ini menggunakan teknik analisis regresi linear sederhana untuk menguji hipotesis penelitian. Data yang diperoleh kemudian dianalisis menggunakan SPSS 2.5 for windows.

\section{Hasil}

Subjek dalam penelitian ini adalah 300 karyawan tetap dan karyawan non-tetap dari 4 jenis perusahaan yaitu; 1) perusahaan jasa swasta, 2) perusahaan jasa pemerintah, 3) perusahaan produksi swasta, 4) perempuan 47,3\%. Selanjutnya, ditinjau dari usia jumlah subjek terbanyak berada pada rentang usia 18-28 tahun sejumlah 203 orang $(67,7 \%)$, disusul kemudian 29-39 sejumlah 66 orang (22\%), usia 40-50 tahun sejumlah 20 orang $(6,7 \%)$, usia 51-60 tahun sejumlah 11 orang $(3,6 \%)$. Kemudian, data keseluruhan karyawan memiliki masa kerja yang berbeda-beda, mayoritas karyawan memiliki masa kerja yakni diantara 1-5 tahun sebanyak 214 orang $(71,3 \%)$, sisanya masa kerja $>5$ tahun sejumlah 86 orang $(28,7 \%)$. Pada status kerjanya, mayoritas karyawan berstatus karyawan sebanyak 155 orang $(51,7 \%)$ orang, sisanya dengan status tidak tetap 145 orang (48,3\%). 
Selanjutnya, nilai rata-rata (Mean) dan nilai standar deviasi (SD), kategorisasi skor perceived organizational support dan work engagement dapat dilihat pada Tabel 2.

Tabel 2 menjelaskan hasil uji statistik deskriptif didapatkan hasil bahwa variabel perceived organizational support memiliki mean 36,3 dengan standar deviasi 6,986 yang data demografi subjek, diketahui bahwa baik laki-laki atau perempuan sama-sama berada dalam kategori sedang. Selanjutnya berdasarkan usia subjek, mayoritas berusia 18-28 tahun hingga 51-60 tahun memiliki skor perceived organizational support kategori sedang. Demikian pula berdasarkan masa kerja karyawan dengan masa kerja 1-5

Tabel 2.

Deskripsi dan Kategorisasi Variabel Penelitian

\begin{tabular}{|c|c|c|c|c|c|c|}
\hline Variabel Penelitian & Mean & $S D$ & Kategori & Interval & Frekuensi & $\begin{array}{c}\text { Persentase } \\
(\%)\end{array}$ \\
\hline \multirow{3}{*}{$\begin{array}{c}\text { Perceived } \\
\text { Organizational } \\
\text { Support }\end{array}$} & \multirow{3}{*}{36,3} & \multirow{3}{*}{6,986} & Tinggi & $>43$ & 48 & $16 \%$ \\
\hline & & & Sedang & $29-42$ & 193 & $64,3 \%$ \\
\hline & & & Rendah & $<29$ & 59 & $19,7 \%$ \\
\hline \multirow{3}{*}{ Work Engagement } & \multirow{3}{*}{52,32} & \multirow{3}{*}{6,711} & Tinggi & $>59$ & 62 & $20,7 \%$ \\
\hline & & & Sedang & $46-58$ & 208 & $69,3 \%$ \\
\hline & & & Rendah & $<46$ & 30 & $10 \%$ \\
\hline
\end{tabular}

berarti rata-rata subjek menjawab tiap item berada di rentang nilai kategori sedang. Selanjutnya, untuk variabel work engagement memiliki rata-rata sebesar 52,32 dengan standar deviasi 6,711 yang berarti rata-rata subjek menjawab tiap item berada di rentang kategori sedang.

Berdasarkan kategorisasi variabel penelitian di Tabel 2, data keseluruhan subjek memiliki skor perceived organizational support sejumlah 48 orang (16\%) dengan rentang kategori tinggi, sejumlah 193 orang $(64,3 \%)$ masuk kategori sedang 59 orang $(19,7 \%)$ masuk dalam kategori kategori rendah. Sedangkan pada work engagement sejumlah 62 orang $(20,7 \%)$ berada pada kategori tinggi, 208 orang $(69,3 \%)$ masuk kategori sedang 30 orang $(10 \%)$ kategori rendah.

Data uji tabulasi silang pada Tabel 3. memaparkan bahwa variabel perceived organizational support jika ditinjau dari data- tahun hingga $>5$ tahun, mayoritas memiliki skor perceived organizational support yang berada pada rentang kategori sedang. Selanjutnya, berdasarkan status karyawan dengan klasifikasi karyawan tetap dan nontetap mayoritas memiliki skor perceived organizational support yang berada pada rentang kategori sedang.

Melalui uji regresi linier yang diperoleh nilai koefisien korelasi sebesar 0,582, artinya ada korelasi yang searah antara perceived organizational support dan work engagement. Hal ini menunjukkan semakin tinggi perceived organizational support yang dimiliki oleh karyawan, maka semakin tinggi pula work engagement yang dimiliki. Korelasi antara kedua variabel tersebut sangat kuat, hal ini dapat dilihat dari angka koefisien korelasi $(r)>0,5-0,75$ (Sarwono, 2006). Selanjutnya, sumbangan efektif yang diberikan oleh variabel perceived organizational support terhadap 
variabel work engagement sebesar 33,8\% dengan nilai koefisien determinasi 0,338 , di mana sisa $66,2 \%$ dipengaruhi oleh faktor lain yang tidak diuji dalam penelitian ini. Selanjutnya, nilai signifikansi yang diperoleh menunjukkan hipotesis diterima, yakni perceived organizational support terbukti memiliki peran terhadap work engagement dengan nilai $(p)<0,05$.

Tabel 3.

Uji Tabulasi Silang Variabel Penelitian support memiliki peran terhadap work engagement karyawan. Peran spesifik perceived organizational support adalah mampu menentukan kadar tinggi rendahnya work engagement yang dimiliki karyawan. Semakin positif perceived organizational support maka akan berbanding lurus dengan positifnya kadar work engagement karyawan. Begitu juga sebaliknya, semakin negatif perceived

\begin{tabular}{|c|c|c|c|c|c|c|c|c|c|c|c|c|}
\hline & \multicolumn{6}{|c|}{$\begin{array}{c}\text { Perceived Organizational Support } \\
\text { (POS) }\end{array}$} & \multicolumn{6}{|c|}{ Work Engagement (WE) } \\
\hline & \multicolumn{2}{|c|}{ Tinggi } & \multicolumn{2}{|c|}{ Sedang } & \multicolumn{2}{|c|}{ Rendah } & \multicolumn{2}{|c|}{ Tinggi } & \multicolumn{2}{|c|}{ Sedang } & \multicolumn{2}{|c|}{ Rendah } \\
\hline & $\mathbf{F}$ & $\%$ & $\mathbf{F}$ & $\%$ & $\mathbf{F}$ & $\%$ & $\mathbf{F}$ & $\%$ & $\mathbf{F}$ & $\%$ & $\mathbf{F}$ & $\%$ \\
\hline \multicolumn{13}{|l|}{ Gender } \\
\hline Laki-Laki & 35 & 11,7 & 109 & 36,3 & 14 & 4,7 & 27 & 9 & 99 & 33 & 32 & 10,7 \\
\hline Perempuan & 27 & 9 & 99 & 33 & 16 & 5,3 & 21 & 7 & 94 & 31,3 & 27 & 9 \\
\hline TOTAL & 62 & 20,7 & 208 & 69,3 & 30 & 10 & 48 & 16 & 193 & 64,3 & 59 & 19,7 \\
\hline \multicolumn{13}{|l|}{ Usia } \\
\hline 18-28 Tahun & 36 & 12 & 133 & 44,3 & 34 & 11,3 & 43 & 14,3 & 141 & 47 & 19 & 6,3 \\
\hline 29-39 Tahun & 8 & 2,6 & 38 & 12,7 & 20 & 6,7 & 13 & 4,3 & 45 & 15 & 8 & 2,7 \\
\hline 40-50 Tahun & 2 & 0,7 & 14 & 4,7 & 4 & 1,3 & 3 & 1 & 15 & 5 & 2 & 0,7 \\
\hline 51-60 Tahun & 2 & 0,7 & 8 & 2,7 & 1 & 0,3 & 3 & 1 & 7 & 2,3 & 1 & 0,3 \\
\hline TOTAL & 48 & 16 & 193 & 64,4 & 59 & 19,6 & 62 & 20,6 & 208 & 69,3 & 30 & 10 \\
\hline \multicolumn{13}{|l|}{ Masa kerja } \\
\hline 1-5 Tahun & 33 & 11 & 139 & 46,3 & 42 & 14 & 43 & 14,3 & 148 & 49,3 & 23 & 7,7 \\
\hline >5 Tahun & 15 & 5 & 54 & 18 & 17 & 5,7 & 19 & 6,3 & 60 & 20 & 7 & 2,3 \\
\hline TOTAL & 48 & 16 & 193 & 64,3 & 59 & 19,7 & 62 & 20,6 & 208 & 69,3 & 30 & 10 \\
\hline \multicolumn{13}{|c|}{ Status Karyawan } \\
\hline Non-Tetap & 24 & 8 & 96 & 32 & 25 & 8,3 & 30 & 10 & 100 & 33,3 & 15 & 5 \\
\hline Tetap & 24 & 8 & 97 & 32,3 & 34 & 11,3 & 32 & 10,7 & 108 & 36 & 15 & 5 \\
\hline TOTAL & 48 & 16 & 193 & 64,3 & 59 & 19,6 & 62 & 20,7 & 208 & 69,3 & 30 & 10 \\
\hline
\end{tabular}

\section{Diskusi}

Penelitian ini bertujuan untuk mengetahui peran perceived organizational support terhadap work engagement karyawan. Hasil analisis data menunjukkan bahwa uji hipotesis diterima, (Nilai $F=152,442, P=$ $<0,005)$. Artinya, perceived organizational organizational support maka akan menentukan berkurangnya kadar work engagement karyawan. Dengan demikian temuan membuktikan penelitian terdahulu bahwasanya perceived organizational support merupakan salah satu faktor yang dapat meningkatkan kadar work engagement pada karyawan. 
Hasil dari penelitian ini mendukung penelitian sebelumnya yang dilakukan oleh Sitanggang (2018) yang mengemukakan bahwa terdapat pengaruh positif perceived organizational support terhadap work engagement karyawan dengan sumbangan efektif mencapai 4,5\%. Hubungan yang kuat antara perceived organizational support dan work engagement juga ditemukan di berbagai penelitian lain secara konsisten (Caesens \& Stinglhamber, 2014; Dai \& Qin, 2016). Konsistensi temuan ini mempertegas adanya hubungan yang kuat antara kedua variabel yang diteliti sehingga layak untuk mendapatkan perhatian bagi praktisi maupun peneliti yang fokus pada industrial organization dan human resource, khususnya instansi atau perusahaan yang sangat tergantung terhadap sumber daya manusianya.

Menurut Rhoades dan Eisenberger (2002), terciptanya work engagement pada karyawan bisa dijelaskan melalui Social Exchange Theory (SET). SET adalah sebuah timbal balik antara karyawan dengan perusahaan, di mana ketika karyawan menerima sumber-sumber yang penting dari organisasi, maka karyawan akan merasa berkewajiban membayar atau memberikan kinerjanya terhadap organisasi. Artinya ada hubungan timbal balik yang saling menguntungkan antara organisasi dan karyawan sebagai subjek yang menunjukkan perilaku organisasi (Coyle-Shapiro \& Shore, 2007; Galankis, Mouraitou, Garrivaldis, \& Stalikas, 2009).).

Wujud organizational support terbagi menjadi tiga kategori utama, yaitu keadilan, keberpihakan organisasi, penghargaan, dan kondisi kerja (pelatihan, otonomi, dan stres kerja), dan dukungan supervisor yang dianggap bertindak sebagai perwakilan organisasi (Rhoades \& Eisenberger, 2002). Apabila karyawan mendapatkan berbagai wujud organizational support tersebut, dampaknya adalah karyawan merasa memiliki kewajiban dalam dirinya untuk membalas dengan kebaikan yang serupa, disamping itu kebutuhan emosional karyawan juga terpenuhi seperti self-esteem dan hadirnya rasa memiliki dan menjadi bagian terhadap organisasi tersebut sehingga terdorong berperan lebih aktif (Rhoades \& Eisenberger, 2002).

Jika ditinjau dari gender, status kerja dan jenis perusahaan baik perceived organizational support maupun work engagement tidak memiliki perbedaan, di mana semua responden memiliki perceived organizational support dan work engagement pada taraf sedang. Artinya responden dalam penelitian ini tidak mengalami kendala yang berarti terkait kedua variabel yang diteliti. Di tempat kerja responden cukup merasa mendapatkan organizational support dan secara personal memiliki kadar work engagement yang cukup baik sehingga memungkinkan kehidupan kerja yang cukup stabil.

Tidak terbuktinya peran gender terhadap work engagement didasarkan pada penelitian terdahulu yang menyebutkan bahwa antara laki-laki dan perempuan tidak memiliki perbedaan terhadap work engagement yang dimiliki (Tshilongamulenzhe \& Takawira, 2015). Meski demikian tidak dipungkiri juga bahwa terdapat inkonsistensi hasil penelitian. Ada beberapa temuan yang 
justru menyatakan bahwa perbedaan gender berpengaruh terhadap work engagement karyawan di mana perempuan cenderung lebih engaged terhadap pekerjaan dibandingkan laki-laki (Gulzar \& Teli, 2018). Namun demikian pada temuan lainnya laki-laki dianggap lebih mudah engaged terhadap pekerjaan dibandingkan perempuan (Banihani, Lewis \& Syed, 2013).

Jika ditinjau dari usia, tidak ada penelitian yang spesifik menyebutkan angka tertentu terkait hubungannya dengan work engagement. Tidak terbuktinya perbedaan usia pada responden penelitian perlu diuji lebih mendalam mengingat ada temuan yang menyatakan hubungan antara usia dan work engagement. Korsakienè, Raišienè, dan Bužavaitè (2017) menyebutkan karyawan dengan durasi kerja lebih lama (senior) dan secara umur lebih matang cenderung terlihat kurang engaged dalam pekerjaan, kurang familiar dengan lifelong learning dan cara mengatasi masalah kesehatan yang memburuk dibandingkan dengan karyawan yang masih muda.

Selaras dengan temuan sebelumnya, durasi lama bekerja tidak dapat dibuktikan pada responden penelitian ini, namun demikian hasil penelitian terdahulu tidak konsisten. Durasi lama bekerja erat kaitannya dengan usia karyawan sehingga idealnya temuan-temuan antara usia dan durasi lama bekerja selaras dan tidak saling bertentangan. Kurniawati menyebutkan durasi lama bekerja dianggap berpengaruh terhadap work engagement, di mana dari masa kerja dapat melihat pemahaman karyawan terkait bidang yang ditekuni, dan pemahaman terhadap visi dan misi perusahaan sehingga ide-ide yang disampaikan berkesinambungan dengan pekerjaan yang ditangani, dan membuat lebih fokus dalam bekerja, serta selalu ingin memberikan yang terbaik untuk perusahaannya.

Temuan tersebut berbeda jika dibandingkan dengan usia karyawan yang berkaitan dengan perbedaan karakteristik generasi. Baik karyawan yang memiliki durasi bekerja yang tergolong lama dan baru masing-masing memiliki ciri tertentu berdasarkan golongan generasinya, ekspektasi dan orientasi kerja yang dimiliki (Fawazi, 2013). Pada generasi muda dianggap lebih kreatif, manja, ambisius dan sedang berada pada tahap perintisan karier sehingga lebih membutuhkan arahan dan bimbingan, berbeda dengan generasi yang lebih lama cenderung lebih mandiri, loyal terhadap perusahaan, dan selalu ingin menciptakan keseimbangan dan kenyamanan sosial dalam lingkungan pekerjaan (Geriarti, 2009).

Selanjutnya, pada status pekerjaan tetap dan non tetap meskipun ditemukan perbedaan yang tidak signifikan pada responden penelitian dianggap memiliki pengaruh terhadap work engagement. Karyawan dengan status tetap sudah melalui masa kerja dan masa percobaan sehingga karyawan tersebut dinilai mampu dan layak menjalankan tugas dan jabatan dan layak mendapatkan mendapatkan reward seperti fasilitas, gaji ataupun tunjangan yang tidak didapatkan oleh karyawan dengan status non-tetap. Saks (2006) menyebutkan bahwa reward yang diberikan perusahaan adalah salah satu organizational support yang dapat 
meningkatkan work engagement karyawan. Reward yang didapat karyawan dapat menjadi faktor penentu hadirnya kesadaran diri akan kewajiban selayaknya karyawan terhadap perusahaan.

Secara umum inkonsistensi temuan penelitian terdahulu terkait data demografi dalam penelitian ini dapat dieksplorasi lebih jauh melalui berbagai pengembangan penelitian selanjutnya. Tentu penelitian ini memiliki berbagai kekurangan, yaitu proses pengambilan data yang dilakukan secara online melalui media sosial seperti whatsapp sehingga memungkinkan terjadinya bias dan lemahnya level of control, namun demikian peneliti melakukan upaya agar data yang diperoleh tetap valid dengan melakukan skrining awal sebelum pengisian dengan menyediakan informed consent. Selanjutnya, yang menjadi nilai tambah dari penelitian ini adalah pemaparan data demografi yang turut menjadi fokus kajian sehingga menambah informasi penelitian-penelitian terdahulu terkait faktor-faktor yang memungkinkan turut berperan terhadap work engagement meskipun sampai saat ini temuannya tidak konsisten. Hal ini menjadi peluang bagi peneliti selanjutnya untuk dapat mengembangkan, memvalidasi, dan memperkaya temuan-temuan terkait serta dipadukan dengan kekhasan karakteristik subjek, data demografi, dan variabel lainnya.

\section{Kesimpulan}

Hasil penelitian menunjukkan perceived organizational support berperan terhadap work engagement. Artinya, semakin tinggi perceived organizational support dapat meningkatkan work engagement pada karyawan. Persepsi-persepsi yang dimiliki karyawan dapat menentukan keterlibatan mereka secara penuh terhadap pekerjaan yang sedang ditekuni, entah itu persepsi positif ataupun persepsi negatif. Adapun sumbangan efektif perceived organizational support terhadap work engagement sebesar $33,8 \%$ sedangkan sisanya $66,2 \%$ dipengaruhi oleh faktor-faktor lain yang tidak dimasukan dalam penelitian. Artinya, perceived organizational support cukup kuat di dalam memprediksi work engagement karyawan. Semakin positif perceived organizational support maka semakin positif kadar work engagement karyawan. Begitu juga sebaliknya, semakin negatif perceived organizational support maka semakin negatif work engagement karyawan.

\section{Saran}

Berdasarkan kelemahan dalam penelitian ini saran yang diajukan adalah bagi peneliti selanjutnya dapat mereplikasi penelitian ini pada karakteristik subjek dan lokasi yang berbeda sehingga dapat menambah memperkaya dan memvalidasi temuan untuk melihat inkonsistensinya. Semakin banyak replikasi penelitian yang serupa maka validasi temuan akan semakin akurat. Selanjutnya, perkuat kontrol proses pengambilan data agar informasi yang diperoleh akurat dan terhindar dari bias yang dapat memengaruhi hasil penelitian.

Kemudian, bagi praktisi pemerhati industrial organization dan human resource, 
khususnya instansi atau perusahaan yang sangat bergantung terhadap sumber daya manusia, untuk memperhatikan kedua variabel yang menjadi fokus dalam penelitian ini mengingat banyak literatur yang telah menyebutkan konsistensi hubungan yang kuat antar keduanya. Hal ini dapat menjadi dasar pertimbangan untuk merumuskan kebijakan yang samasama menguntungkan bagi kedua belah pihak.

\section{Daftar Pustaka}

Alkhatiri, F. (2017). Intervensi komitmen organisasional terhadap keputusan keluarnya pegawai dari organisasi non-profit. Journal of Business Studies, 2(2), 66-79.

Amir, M. F. (2015). Memahami evaluasi kinerja karyawan: Konsep dan penilaian kinerja di perusahaan. Jakarta: Mitra Wacana Media.

Anggiadinata, N. S. (2015). Peran theistic sanctification of work terhadap work engagement pada karyawan PT. Krakatau Steel (Persero) TBK. Yogyakarta: Universitas Islam Indonesia.

Banihani, M., Lewis, P., \& Syed, J. (2013). (2013). Is work engagement gendered?. Gender in Management, 28(7), 400-423.

doi:https://doi.org/10.1108/GM-012013-0005

Bakker, A. B., \& Demerouti, E. (2007). The job demands-resources model: State of the art. Journal of Managerial Psychology, 22(3), 309-328. doi: https://doi.org/10.1108/0268394071073 $\underline{3115}$
Bakker, A. B., \& Demerouti, E. (2008). Towards a model of work engagement. Career Development Internasional, 13(3), 209-223. doi: https://doi.org/10.1108/1362043081087 $\underline{0476}$

Caesens \& Stinglhamber. (2014). The relationship between perceived organizational support and work engagement: The role of self-efficacy and its outcomes. European Review of Applied Psychology, 64(5), 259-267. doi: https://doi.org/10.1016/j.erap.2014.08.0 $\underline{02}$

Coyle-Shapiro, J. A-M. \& Shore, L. (2007) The employee-organization relationship: Where do we go from here?. Human Resource Management Review, 17(2), 166-179. doi: https://doi.org/10.1016/j.hrmr.2007.03. $\underline{008}$

Crawford, E. R., LePine, J. A., \& Rich, B. L. (2010). Linking job demands and resources to employee engagement and burnout: A theoretical extension and meta-analytic test. Journal of Applied Psychology, 95(5), 834-848. doi: https://doi.org/10.1037/a0019364

Dai, K. L. and Qin, X. Y. (2016) Perceived organizational support and employee engagement: based on the research of organizational identification and organizational justice. Open Journal of Social Sciences, 4(12), 46-57. doi: http://dx.doi.org/10.4236/jss.2016.4120 $\underline{05}$

Davids, A. (2011). The relationship between work engagement, self-efficacy and optimism among call centre agents (Tesis tidak dipublikasikan). Department of 
Industrial Psychology, University of the Western Cape, Bellville.

Eisenberger, R., Huntington, R., Hutchison, S., \& Sowa, D. (1986). Perceived organizational support. Journal of Applied Psychology, 71(3), 500-507. doi:

https://doi.org/10.1037/0021-

$\underline{9010.71 .3 .500}$

Fatoni, M., Prihatini D., Suryaningsih B., I. (2018). The role of OCB in mediating the effect of employee engagement and organizational commitment on employee performance: Contract vs permanent employees. International Journal of Scientific Research and Management (IJSRM), 6(8), 568-579. doi:

https://doi.org/10.18535/ijsrm/v6i8.el03

Fawazi, A. (2013). Analisis pengaruh ekspektasi kerja generasi $X$ dan generasi $Y$ terhadap efektivitas strategi rekrutmen di PT. Samudera Indonesia (Tesis tidak dipublikasikan). Universitas Bina Nusantara, Jakarta.

Galankis. M., Mouraitou, M., Garivaldis, F. J., dan Stalikas, A. (2009). Factorial structure and psyhometric properties of the Maslach Burnout Inventory (MBI) in Greek midwives. Europe's Journal of Psychology, 5(4), 52-70. doi: https://doi.org/10.5964/ejop.v5i4.240

Geriarti, I. M. (2009). Pengaruh tingkat pendidikan dan masa kerja terhadap prestasi kerja karyawan PT. PLN Area Pelayanan dan Jaringan Malang (Skripsi tidak dipublikasikan). Program Studi Pendidikan Administrasi Perkantoran, Universitas Negeri Malang, Malang.
Gulzar, S., \& Teli, M.R. (2018). Gender and work engagement: A study of academic staff in higher education. Arabian Journal of Business and Management Review, 8(2), 1-3.

Hafiz, M. (2018). Peran kebersyukuran terhadap work engagement pada pegawai aparatur sipil negara kabupaten Sintang Provinsi Kalimantan Barat (Tesis tidak dipublikasikan). Fakultas Psikologi dan Ilmu Sosial Budaya, Universitas Islam Indonesia, Yogyakarta.

Hallberg, U.E. \& Schaufeli, W.B. (2006). "Same same" but different? cam work engagement be discriminated from job involvement and organizational commitment?. European Psychologist, 11(2), 119-127. doi: https://doi.org/10.1027/10169040.11.2.119

Harter, J. K., Schmidt, F. L., \& Hayes, T. L. (2002). Business-unit-level relationship between employee satisfaction, employee engagement, and business outcomes: A meta-analysis. Journal of Applied Psychology, 87(2), 268-279. doi: https://doi.org/10.1037/00219010.87.2.268

Hasibuan, S.P. (2012). Manajemen sumber daya manusia. Jakarta: PT Bumi Aksara.

Hermawan, I. P. D., Hartika, L. D., Simarmata, N. (2017). Hubungan work engagement dengan turnover intention: Studi pada karyawan PT. X. Jurnal Psikologi Mandala, 1(2), 16-22.

John, P. E., \& Pant M. R. (2018). Impact of work engagement on job satisfaction: A study on Faculty of Higher Education in Arunachal Pradesh (India). 
International Journal of Creative Research Thoughts (IJCRT), 6(1), 845-851.

Kahn, A. W. (1990). Psychological conditions of personal engagement and disengagement at work. Academy of Management Journal, 33(4), 692-724. doi: https://doi.org/10.5465/256287

Korsakienè, R., Raišienė, A. G., Bužavaitė, M. (2017). Work engagement of older employees: Do employee and workrelated factors matter? Economics and Sociology, 10(4), 151-161. doi: http://doi.org/10.14254/2071-

\section{X.2017/10-4/12}

Kurniawati, I. D. (2014). Masa kerja dengan job engagement pada karyawan. Jurnal Ilmiah Psikologi Terapan, 2(2), 311-324.

Kusumandaru, I. (2017). Peran persepsi dukungan organisasi terhadap work engagement pada karyawan Rumah Sakit Islam Klaten (Skripsi tidak dipublikasikan). Fakultas Psikologi dan Ilmu Sosial Budaya, Universitas Islam Indonesia, Yogyakarta.

Lockwood, N., 2007. Leveraging employee engagement for competitive advantage: HR's strategic role. Global Journal of Commerce \& Management Perspective, 52(3), 1-11.

Lu, L., Lu, A.C.C., Gursoy, D. and Neale, N.R. (2016). Work engagement, job satisfaction, and turnover intentions: A comparison between supervisors and line-level employees. International Journal of Contemporary Hospitality Management, 28(4), 737-761. doi: https://doi.org/10.1108/IJCHM-07-2014$\underline{0360}$

Lie, V. L., \& Andreani, F. (2017). Analisis gap antara harapan dan persepsi karyawan tentang keadilan organisasi di PT Kali Jaya Putra. Agora, 5(1), 1-6.

Mewengkang, M., \& Panggabean, H. (2016). Work engagement karyawan MRN terhadap implementasi aplikasi data analisis SDM. Jurnal Ilmiah Psikologi Manasa, 5(1), 1-14.

Mustofa, D. N. A. (2019). Hubungan antara job crafting dengan work engagement pada karyawan. (Skripsi tidak dipublikasikan). Universitas Muhammadiyah Malang, Malang.

Priyono \& Marnis (2008). Manajemen sumber daya manusia. Sidoarjo: Zifatama Publisher.

Rhoades, L., \& Eisenberger, R. (2002). Perceived organizational support: A review of the literature. Journal of Applied Psychology, 87(4), 698-714. doi: https://doi.org/10.1037/0021-

$\underline{9010.87 .4 .698}$

Robert, M., (2006). Stress in the work place (Edisi pertama). New Jersey: Pearson Publisher.

Rotich, R. K., Cheruiyot, T. K., \& Korir, M. K. (2016). Effects of demographics on the relationship between optimism and work engagement among employees of state agencies in Kenya. Journal of Resources Development and Management, $18,32-42$.

Saks, A.M. (2006). Antecedents and consequences of employee engagement. Journal of Managerial Psychology, 21(6), 600-619. doi: https://doi.org/10.1108/02683940610690 $\underline{169}$

Sarwono, J. (2006) Metode penelitian kuantitatif dan kualitatif. Yogyakarta: Graha Ilmu. 
Schaufeli, Salanova, Roma, V. G., \& Bakker, A. (2002). The measurement of engagement and burnout: a two sample confirmatory factor analytic approach. Journal of Happiness Studies, 3 , 71-92.

doi: https://doi.org/10.1023/A:101563093032 $\underline{6}$

Schaufeli, W.B., \& Bakker, A.B. (2004). Job demands, job resources, and their relationship with burnout and engagement: A multi-sample study. Journal of Organizational Behavior, 25, 293-315. doi: https://doi.org/10.1002/job.248

Sekhar, C., Patwardhan, M., \& Vyas, V. (2018). Linking work engagement to job performance through flexible human resource management. Advances in Developing Human Resources, 20(1), 7287. doi: https://doi.org/10.1177/15234223177432 $\underline{50}$

Shehri A. M., McLaughlin P., Al-Ashaab A., Hamad R. (2017). The impact of organizational culture on employee engagement in Saudi Banks. Journal of Human Resources Management Research.
2017,

1-23.

doi:

http://doi.org/10.5171/2017.761672

Sitanggang, F. T., (2018). Pengaruh persepsi dukungan organisasi terhadap keterikatan kerja pada karyawan marketing PT. Infomedia Nusantara (Skripsi tidak dipublikasikan). Fakultas Psikologi, Universitas Sumatera Utara, Medan.

Tshilongamulenzhe, M.C \& Takawira, N. (2015). Examining the gender influence on employees' work engagement within a South African University. Risk Governance and Control: Financial Markets E Institutions, 5(2), 110-119. doi: http://dx.doi.org/10.22495/rgcv5i2c1art $\underline{5}$

Sugiyono. (2010). Metode penelitian kuantitatif kualitatif dan RED. Bandung: Alfabeta.

Okoye, P.V.C., \& Ezejiofor, R.A. (2013). The effect of human resources development on organizational productivity. International Journal of Academic Research in Business and Social Sciences, 3(10), 250-268.

doi: http://dx.doi.org/10.6007/IJARBSS/v3$\underline{\mathrm{i} 10 / 295}$ 